Journal of the Scholarship of Teaching and Learning, Vol. 20, No. 2, October 2020, pp. 122-126.

doi: 10.14434/josotl.v20i2.24386

\title{
Integrating the Daily Newspaper into the College Classroom
}

\author{
Zachary Schrank \\ Indiana University South Bend \\ zschrank@iusb.edu
}

\begin{abstract}
This Quick Hit discusses an exploratory approach to integrating print newspaper into the college classroom as a method to connect journalism with theoretical knowledge. Daily copies of The New York Times were provided to students in an Introductory Sociology course throughout the duration of a semester. Working in groups, students regularly read articles in the paper and searched for stories related to a wide variety of sociological issues. As a final project, students wrote detailed summaries of several articles published throughout the semester that contained key sociological concepts and themes studied in the class. Nearly all students in the course reported that consistent readership over a 12-week period of the semester was an effective learning activity that expanded their understanding and exposure to core sociological issues.
\end{abstract}

Keywords: newspaper readership, introduction to sociology, real-world application, current events.

\section{Introduction}

Newspaper readership has declined considerably over the past two decades among younger generational cohorts (Poindexter 1979; Pew Research Center 2016). Only 16 percent of Millennials and students of college age report reading any daily newspaper (Pew Research Center News Media Indicators Database 2016). This development comes at a particularly vexing time with American society highly polarized along political and cultural lines. Fake news also played a prominent role in the 2016 general election and appears to be on the incline (Allcott and Gentzkow, 2017). Not only is newspaper consumption on the decline, but much of today's news is now filtered through online social media platforms, highly fragmented, inaccurate, misleading, or purposely false (Gottfried and Shearer 2016). Over time, the public has become less aware of national and global events and people have difficulty making connections between their lives and the larger social forces that influence their surrounding circumstances.

This Quick Hit discusses an approach to teaching I use that incorporates daily digital and print copies of the news into an Introductory Sociology class. I found that assigning a subscription to The New York Times as supplemental reading engaged student interest and experiences in a way that assisted in deeper conceptual understanding of the course material (National Research Council 1999, 10-17). The New York Times frequently contains stories rich with sociological themes and previous studies have found that students greatly benefit from newspaper readership throughout the semester as a way of promoting active learning (Reinertsen and DaCruz, 1996; Knowlton and Barefoot, 1999; Mysliwiec, Shibley Jr., and Dunbar, 2002). By integrating print and digital media into the course, students could make tangible connections between abstract sociological concepts with stories about real people and their external social experiences (Faust and Donald, 1998). Their comprehension of core sociological issues (such as class, race, gender, culture, work, sexuality, and globalization) was matched with direct examples of current events covered in the news. 


\section{The Project}

I teach Introductory Sociology at a public university and decided to incorporate digital subscriptions and print copy of The New York Times because of its extensive student readership programs. As part of this class project, I required students to obtain a digital subscription and a hard copy of the paper at least twice per week. Over the semester students were expected to read the paper regularly and be alert to stories related to a list of sociological issues and concepts that we would discuss throughout the class (see Table 1). When students came across articles that contained sociological content we covered during the semester, they were instructed to cut them out and save them in a project folder.

One of the goals guiding the project was for students to get a sense of the vast amount stories that were built around sociological themes. I organized the class into nine separate small groups with five students in each. This teamwork helped students share ideas and cooperate on this active learning project (Chickering and Gamson, 1989). Scholars of teaching and learning have also noted that the process of "commenting on a relevant newspaper article" in small groups can make course material easier for students to comprehend and apply (Billson, 1998:148). During class every few days, students broke into their groups and discussed articles with sociological topics.

At the end of the semester each group was expected to select 25 unique stories comprised by at least 15 different sociological topics. Groups were required to include a summary of each story that explained the specific way a sociological concept was expressed, why it was important, and how it provided the tools to better understand the content. Finally, each group arranged the print articles along with summaries as a collage onto large poster boards. Groups presented these posters to the rest of the class so that we could see a diverse cross section of "sociology in the news" over the semester. In total, students in the class collected over 100 unique articles that contained the topics listed Table 1.

\section{Table 1. Sociological Topics Students Identified When Collecting Stories from The New York Times.}

Inequality
Wealth, Poverty, and Social Mobility
Class
Immigration
The American Dream
Wages and Productivity
Sex and Gender
Female Representation
The Glass Ceiling
Gender Typing in the Economy and Female Labor
Integration
Work and Employment / Jobs
Corporations
Family
Race/Ethnicity and Racism
Religion

Scapegoating
Prejudice and Discrimination
Racial Segregation and Structural Inequalities
LGBT Inclusivity
Age
Culture
Deviance and Crime
Globalization
Technology
Population
Environmentalism
Media and Communication
Socialization
Consumerism and Branding
Innovation and Change

Journal of the Scholarship of Teaching and Learning, Vol. 20, No. 2, October 2020. josotl.indiana.edu 


\section{Reflections on the Project}

Persistent readership of The New York Times enhanced students understanding of sociology in their lives and helped them become more aware of diverse social conditions. Many of the stories students read were about struggles for basic survival, the experience of war and migration, human rights abuses, and deep inequality. Several students stated that before they had been exposed to the content of the newspaper they did not care about national and global events simply because they were not aware of them and had no idea how they applied to their personal lives. However, when connecting these stories with sociological concepts, students often voiced desire to use what they were learning in the classroom to take positive social action to address social problems. For example, one student explained:

"It made me super aware of things going outside my inner circle, and the things that were happening around me affected me, and I need to be knowledgeable so I can stand up against these issues that are affecting me and others negatively."

At the conclusion of the semester students were asked to complete an optional anonymous questionnaire regarding their experiences reading the newspaper. 35 of the 45 students who enrolled in the course responded with qualitative remarks. 29 of the students who responded felt "positive", "interested", or "enjoyed" the working through the project. Some even expressed a desire to continue subscribing to a newspaper in the future:

"Reading the NY Times helped me learn about a lot of issues that America faces that I wouldn't have known without reading the NY Times. I will continue my subscription even after this class."

Other students explained that they had developed a greater appreciation for reading the paper after the completion of this project:

"I normally would never have even glanced at a newspaper. But with this project I found that there are some really interesting stories in the paper."

"I am not one who sits down often enough to read the paper. I did not realize how much I was out of touch with world issues before taking this class. I hope to do better about staying informed through sources like The New York Times in the future."

Most students discussed their experience with the project in very positive terms. Many noted that reading this paper nicely complemented the sociological issues we covered over the semester and enhanced their understanding of course material. For example, two additional students provided the following thoughts:

"It was interesting to hear about world events that actually related to what I was learning about in class. It made learning more intriguing and held my attention better."

"I was surprised to see what is happening around the world, because before taking 
this class I never read the newspaper and, therefore, never knew how much really went on in our world."

In many ways, persistent readership also illuminated the extensive nature of sociology itself. Students were surprised with the numerous examples and ways in which social processes we learned about in class were enacted throughout the world. Perhaps this was one of the greatest strengths of the project. It demonstrated to students that sociology is everywhere and we can encounter it in nearly every sphere of society. Here are three student comments that highlight this strength:

"I never really realized how much sociology is in our lives every day until after hearing the professor talk about it and connecting it with current events. After taking this class, I see things I didn't see before, especially because of the newspaper project."

"I enjoyed reading The New York Times because it allowed my sociological imagination to grow. It helped me learned about my community and the places around me."

"Reading The New York Times helped me to relate real-world situations to sociological concepts and helped me understand how sociology impacts many aspects of my life."

In this regard, the project served a dual purpose for students. It activated their conceptual understanding of sociology through the encounter of the daily flow of events. In return, this understanding helped bring meaning to the news itself. It also forced students to examine their individual lives and experiences by considering structures that influence human behavior and life outcomes in ways that are difficult to detect.

\section{Conclusion}

Integrating print copies of The New York Times into the college classroom, particularly an Introductory Sociology course, is a great way to expand the scope of class discussion and analysis. It is also an excellent way to encourage students to become more aware of the expansive social world that influences their daily lives and build an effective sociological imagination to understand social forces and processes. Current events can often appear random, feel chaotic, and be difficult to interpret without foundational historical and sociological competency. Concurrently, sociological concepts can be abstract and challenging to comprehend if they are disconnected from real-world events and activities. However, combining credible news reporting and analysis with sociological concepts can yield promising results in building a student's perspective and enhancing their understanding of our incredibly diverse world. Students in this exploratory project, many of whom had never read The New York Times, found it to be a rewarding way to discover sociology. It was a fun and exciting method for introducing sociological concepts and is likely an effective way to inspire students to become more active and knowledgeable citizens in our democracy.

\section{Acknowledgements}

I would like to thank UCET (University Center for Excellence in Teaching) at IUSB for the MALT (Materials for Active Learning Techniques) Grant I used to fund the delivery of newspaper subscriptions for students in the class where I developed this project. 


\section{References}

Allcott, H. and Gentzkow, M. (2017). Social media and fake news in the 2016 election. Journal of Economic Perspectives, 31(2), 211-236.

Billson, J. (1986). The college classroom as a small group: Some implications for teaching and learning. Teaching Sociology, 14(3), 143-151.

Chickering, A. and Gamson, Z. (1987). The American Association for Higher Education Bulletin. March.

Faust, J., and Paulson, D. (1998). Active learning in the college classroom. Journal on Excellence in College Teaching, 9(2), 3-24.

Gottfried, J. and Shearer, E. (2016). News use across social media platforms 2016. Pew Research Center. Washington, DC: Retrieved May 27, 2016, from http://www.journalism.org/2016/05/26/news-use-across-social-media-platforms-2016/.

Knowlton, S. and Barefoot, B. (1999). Using National Newspapers in the College Classroom: Resources to Improve Teaching and Learning. National Resource Center for The First-Year Experience and Students in Transition. Columbia, S.C.: University of South Carolina.

Mysliwiec, T., Shibley Jr., I., and Dunbar, M. (2003). Using newspapers to facilitate learning. Journal of College Science Teaching, 33(3), 24.

National Research Council. (1999). "How People Learn: Bridging Research and Practice." Washington, DC: National Academy Press.

Park, H., Keller, J., and Williams, J. (2016). "The faces of American power, nearly as white as the oscar nominees." The New York Times. February 26.

Pew Research Center. (2016). "State of the news media 2016." Washington, DC: Retrieved April 13, 2017, from https://assets.pewresearch.org/wpcontent/uploads/sites/13/2016/06/30143308/state-of-the-news-media-report-2016final.pdf.

Pew Research Center. (2016). "Newspapers: Daily readership by age." News Media Indicators Database. Washington, DC: Retrieved April 14, 2016, from http://www.journalism.org/mediaindicators/newspapers-daily-readership-by-age/

Reinertsen, P. and DaCruz, G. (1996). Using the daily newspaper and journal writing to teach large introductory sociology classes. Teaching Sociology, 24, 102-107. 